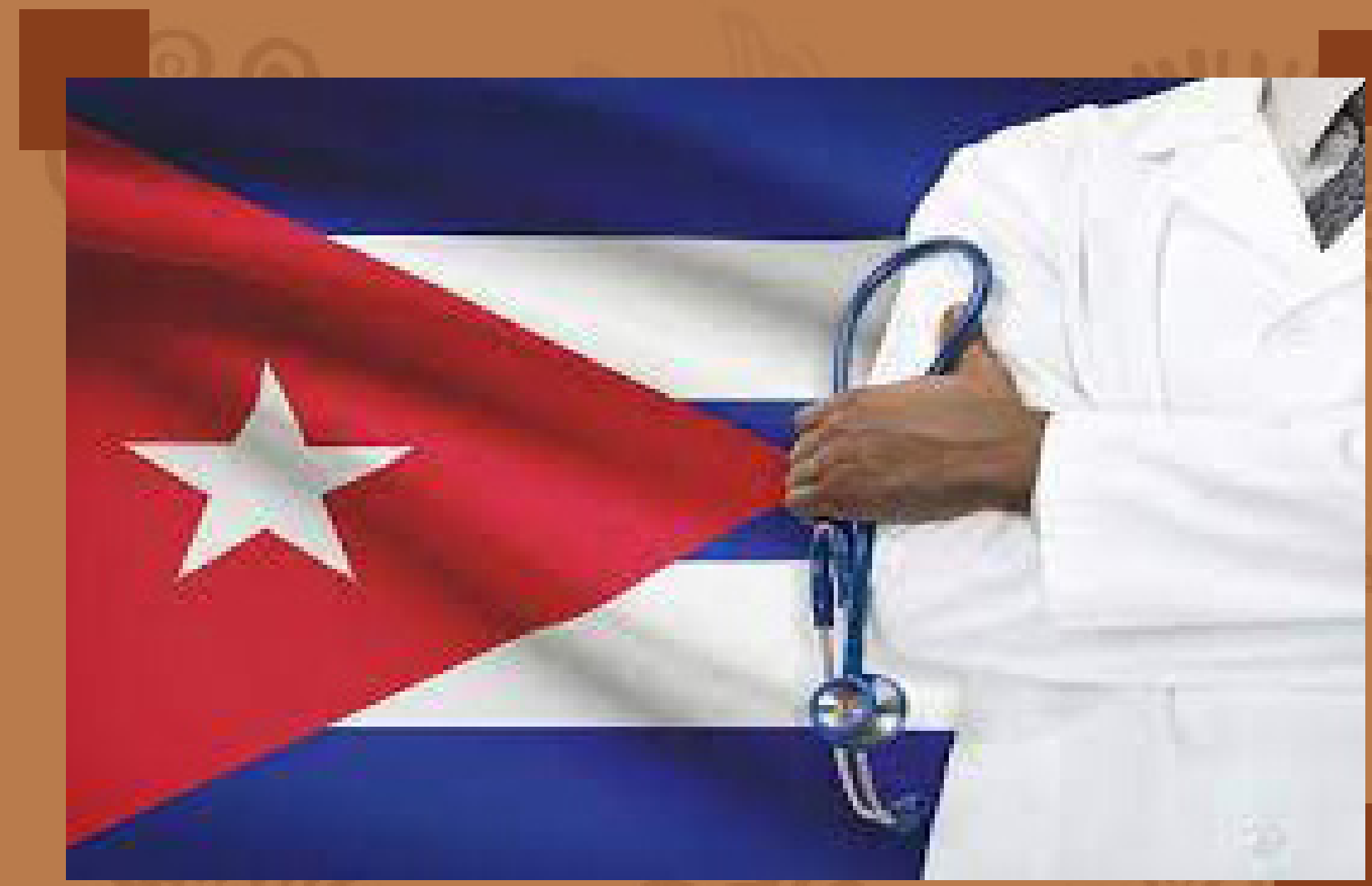

El médico negro de los pobres: Un estudio necesario

Antropologia de la Salud 


\section{El médico negro de los pobres: Un estudio necesario}

The Black Doctor of the Poor: A Necessary Study

Pavel Revelo Álvarez.

Universidad de Camagüey "Ignacio Agramonte Loynaz" Departamento de estudio sociocultural. Profesor auxiliar y jefe de disciplina de desarrollo y políticas sociales. ID Orcid https://orcid.org/0000-0002-1397-7940 pavel.revelo@reduc.edu.cu
Recibido: 02-05-2021

Aceptado: 19-05-2021

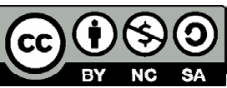

Copyright $\odot 2021$ UNAN-Managua Todos los Derechos Reservados.

\author{
Maricarmen Acuña Pontón \\ Oficina del Historiador de la Ciudad de Camagüey (OHCC) \\ Especialista en procesos sociales de Gestión. \\ ID Orcid https://orcid.org/0000-0001-7667-5045 \\ maria.acuña@nauta.cu
}

\section{Resumen}

El trabajo tiene como objetivo describir aspectos significativos de la vida social y profesional de Fernando Ramón Bastián Milán, un connotado galeno negro, que se desempeñó en la práctica médica a partir de 1938, año en que se tituló en Francia, hasta 1992 cuando decide dejar de consultar oficialmente en el Policlínico Centro. Se utilizaron métodos teóricos como la revisión documental y bibliográfica, también fueron aplicadas entrevistas a familiares, amigos y exalumnos de Bastián Milán. La investigación se centra en resaltar la vida social, cultural y profesional de un médico camagüeyano que priorizó en su quehacer asistencial a las personas de más bajos ingresos económicos. Queda valorada su contribución social en la asistencia brindada a los más pobres y discriminados.

Palabras claves: médico, pobres, negro, antropología, equidad, inclusión.

\section{Abstract}

The objetive of the research is describe some significant aspect of the social and professional life of Fernando Ramón Bastián Milán, a well-known black doctor who start to practice medicine in Camagüey since 1938, after his graduation in France, until 1992, year of his retirement in the Medical Clinic Centre. In this work it used theoretic method such as documents and bibliographic revision, it also applied interview to some member of his family, friends and Bastián Milán's ex-students.

The research it focuses in the siciocultural and professional's life of this camagüeyan doctor, who supported poor people. It valued his medical social contribution give it to discriminated and poor people.

Keywords: doctor, poor, black, Anthropology, equity, inclusion. 


\section{Introducción}

La sociedad cubana decimonónica no vivió ajena al resto del mundo, sobre ella pesaba el estigma socio antropológico de un determinismo racial que condicionó las oportunidades y niveles de acceso a grupos sociales que poseían un tipo de color de piel. En el siglo XX, a pesar de que existieran leyes contra la discriminación sobrevivieron los prejuicios. Muy pocos negros en el país pudieron asistir a la escuela y por ende profesionalizarse.

En la provincia de Camagüey, lugar donde se realiza la investigación, durante el período republicano, sobretodo, hasta la primera década del siglo XX se tienen pocas noticias de graduaciones de médicos de color de piel negra. Estos, al parecer, no necesitaban estudios pues habían sido pensados para los oficios y el mundo fabril, garantizando la reproducción de la división socioclasista del trabajo.

En 1899 en Puerto Príncipe, primer nombre que tuvo la villa, contaba con un total de 46 médicos; de ellos solo uno era negro, (Sanger:1899;488) cifra que comienza a ascender a partir de 1916 en que se gradúa la primera mujer negra, Anastasia Cruz Angulo Verdesi, en ejercicio profesional a partir del 24 de septiembre de1919 (Colegio Médico de Camagüey:1939, 42-43).

La actividad económica fundamental que se desarrolló en esta zona del país fue la ganadería, los negros no estuvieron muy vinculados ni con la plantación, ni con el trapiche de los ingenios, esto propició que el esclavo y los obreros hombres se vieran obligados a instruirse y adiestrarse para el desempeño laboral en algunos oficios, devaluados por el mundo blanco.

Estos se emplearon como: maestros, sastres, carpinteros y las mujeres, en gran número, asumieron el trabajo a domicilio como sirvientas para ayudar a la sobrevivencia de la familia, además de hacerse: enfermeras, maestras, despalilladoras, revendedoras, tejedoras, zapateras, confiteras, empleada de telegrafía y telefonía, ebanistas y costureras, (Conde: 2017, p.87) roles de género asignados históricamente a uno y otro sexo. Estas condicionantes sociales contribuyeron a que, en esta región del país, a consecuencia del caudal económico que se fue acumulando, emergiera una fuerte burguesía negra y mestiza. (García: 2013, Pág 145).

En Camagüey se realizaron esfuerzos ingentes porque los negros se profesionalizarán, ejemplo de ello fueron las asociaciones de instrucción y recreo para negros y mulatos que surgieron en este período y se dirigieron a lograr la promoción humana en este sector poblacional, aunque "dichas instituciones constituían de manera no acabada proyectos educacionales." (García:2013, p.145) A partir de la década del '30 del siglo XX, los negros y mulatos ya estaban muy representados en profesiones y en diversas disciplinas, sin embargo, este crecimiento numérico como apunta De la Fuente (2014) se percibió, como una amenaza a la capacidad de los blancos de controlar el acceso a los trabajos lucrativos. 
Los grandes cambios políticos de la era republicana no acarrearon una franca ruptura con el pasado colonial, y los prejuicios que vinculaban a los negros con una condición social y cultural pobre, persistieron, (Duarte:2013,p.49) era muy difícil que un negro o mulato pudiera ejercer en la ciudad después de haberse titulado, casi todos eran ubicados en el ámbito rural, como ayudantes de otros profesionales o comenzaban a trabajar en otras áreas esperando a ser llamados. Sin embargo algunos negros de sociedad, como fueron los casos de los doctores en medicina, Demetrio Patrocinio Diego Carbonell Céspedes y Fernando Ramón Bastián Milán, en la ciudad de Camagüey, pudieron laborar con el Estado desde sus inicios y mantuvieron consultas privadas, incluso hasta después del triunfo de la Revolución Cubana cuando ya atendían a sus pacientes de forma gratuita.

En la pesquisa bibliográfica realizada se afirma que no se ha publicado en la literatura especializada, ni desde el punto de vista médico, ni histórico, ningún trabajo que aborde como tema central a la figura de Bastián Milán quien constituye el objeto de investigación de este artículo. Ello conduce a inferir que existe un vacío epistémico en las investigaciones antropológicas relacionadas con la historia de la medicina en la región y el legado de sus principales representantes. El objetivo del presente estudio es describir aspectos significativos de la vida social y profesional de Fernando Ramón Bastián Milán, en un contexto marcado por inequidades y discriminaciones múltiples.

Se realizó una investigación con un enfoque epistémico cualitativo, que a partir de la indagación se propuso encontrar información acerca de la vida social y profesional de Bastián Milán y sus redes sociales relacionales. Se utilizaron métodos teóricos como la revisión documental y bibliográfica. Fueron decisivas las entrevistas a familiares, amigos y exalumnos de la Escuela Normal para Maestros como método cualitativo eficaz para la reconstrucción de la historia social de este hombre grande.

\section{Desarrollo}

\section{Vida sociofamiliar de Fernando Bastián Milán}

Según lo referido en la Inscripción de nacimiento, Fernando Ramón Bastián Milán nació el 31 de agosto de 1911 en Camagüey, en la calle Enrique Villuendas número veintidós y cuarto, el nombre antiguo de esta calle era Nuestra Señora del Rosario y posteriormente se le cambia por Enrique Villuendas, el 6 de noviembre de 1907. (Tamames: 2014, p.206). Otras direcciones en las que residió fueron: Rosa La Bayamesa número 19 , un inmueble propiedad de su madre y luego se traslada a la casa de la Calle Cristo número 10 donde radicó hasta el fin de su vida; además era dueño de otra propiedad, ubicada en la calle Pobre número 373 entre Triana y Corona que se la cedió a Ana Oderta Nápoles, una gran amiga de la familia.

Sus padres fueron Caridad Milán García, ama de casa y Fernando Bastián Betancourt, de oficio sastre y luego con mucho esfuerzo se profesionalizó como abogado. Tuvo un solo hermano, Luis Bastián Milán que murió en un accidente, esta tragedia marcó su vida en la infancia pues su abuela los llevaba a los dos a ver un paseo en la tradicional fiesta carnavalesca del San Juan Camagüeyano cuando un camión se subió a la acera 


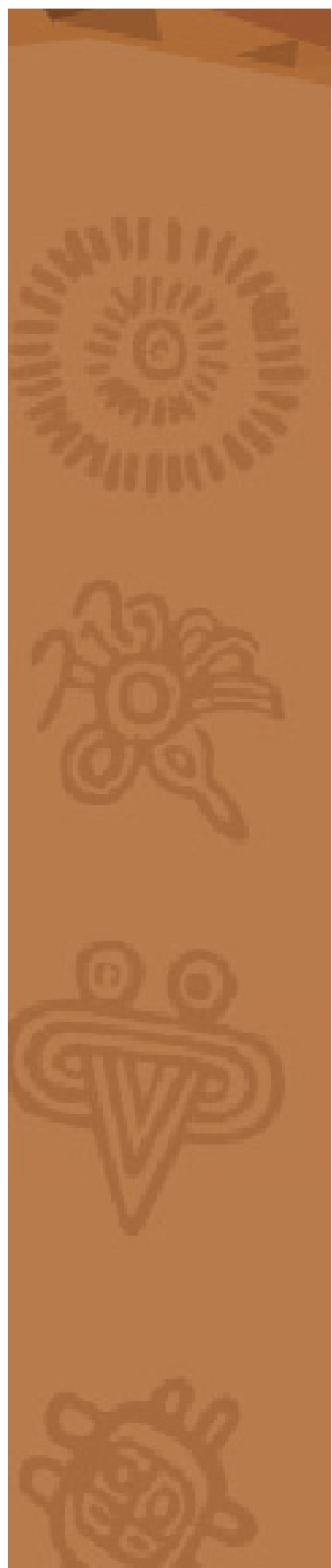

impactando a la abuela y al hermanito los cuales murieron en el instante, ese acontecimiento influyó en su vocación de médico, decía que siempre ayudaría a salvar la vida de las personas.

A pesar de este incidente, tuvo una infancia muy feliz. Su posición social era ventajosa con relación a los blancos pobres y a los negros económicamente inferiores, por estas razones tuvo el privilegio de cursar estudios primarios elementales en una de las academias más prestigiosas de Camagüey, a cargo de un hombre negro también llamado Tomás Vélez Vázquez, lo que evidencia que se venían produciendo ligeros avances en materia de inclusión social y derechos humanos, aunque no se incluían a todos los negros, sino a determinadas familias y personas específicas. Resulta muy arriesgado afirmar que se había producido en esta etapa republicana el triunfo del ideal negro que será un tema que mostrará avances a partir de la década del 30, donde es que comienza a integrarse, de forma incipiente, el componente negro en la nación, como algo propio del cubano, como uno de los componentes étnicos esenciales de la nacionalidad.

El que un negro fuera egresado de colegios religiosos o escuelas privadas laicas de prestigio "les concedía a un pase especial en la sociedad en correspondencia con su nivel de aspiraciones, las cuales respondían a los presupuestos ideológicos en los que habían sido formados, y les proporcionaba, además, cierta conformidad con su realidad de aparente privilegio" (Revelo: 2018, Pág. 754).

El acceso y permanencia a espacios educativos- instructivos escolarizados, caracterizados por altos estándares académicos, elevación del nivel cultural y transmisión de comportamientos aceptados por los normadores, en el caso de las personas no blancas camagüeyanas, quedaron más reservados para las mujeres, que sí contaban desde los primeros años hasta niveles superiores con el acompañamiento de las religiosas católicas Hermanas Oblatas de la Providencia quienes se ocuparon de la fundación de un colegio, regentado por monjas negras y para culturizar a las negras pensando en la movilidad ascendente de su grupo social.

No se veía con agrado que en las escuelas de blancos los negros compartieran el mismo espacio y recursos. Y aunque se concedió, casi de forma simbólica, un lugar para instruir a mujeres negras, en este otorgamiento existieron segundas intenciones, se obtenían beneficios durante el proceso de socialización de las féminas, se formaba a potenciales reproductoras-transmisoras de estereotipos en la familia, de esquemas de obediencia y docilidad. No ocurrió lo mismo con los negros del sexo masculino.

Para los varones negros los espacios escolares instructivos legitimadores, dentro de la educación católica y otras instituciones privadas que eran las que instruían con mayor calidad, quedaron vetados en Camagüey y en Cuba, reduciendo de esta forma a la mínima expresión, las posibilidades de que estos evadieran el control social, pudiesen emanciparse, lucharan contra la hegemonía, fuesen agentes de producción más que de reproducción y finalmente pudiesen alcanzar movilidad social ascendente; además ese distanciamiento de los hombres no blancos de la escuela fue una vía más para mantener, sin modificaciones, la estructura socioclasista, el poder y la dominación del mundo blanco, que se encontraba amenazado si los hombres negros lograban empoderarse y ganar los espacios sociales que se les había negado por siglos. 
Los hombres negros a lo más que podían aspirar era asistir a la escuela pública y hasta la primaria elemental; una escuela pública estigmatizada por problemáticas sociales como: hacinamiento, ausentismo, deficiente preparación del profesorado, sexismo en algunas de ellas y precarias condiciones infraestructurales. Luego de concluir estos niveles elementales algunos se conformaban o resignaban con su realidad de destino porque habían aprendido, aprehendido e interiorizado su posición de inferiores dentro de la escala social y la profesionalización no constituía una aspiración, para los otros que pretendían profesionalizarse, comenzaba un camino espinoso donde el negro, a diferencia del blanco tenía que mostrar doblemente su suficiencia para ser reconocido.

Los negros mantenían su condición de estatismo y salvo alguna excepción, como el caso de Bastián Milán escaparon de los estándares de reproducción social. Una de las formas de resistencias fue precisamente la promoción de que negros reconocidos socialmente avalaran a otros con potencialidades y capacidades probadas para impulsarlos humanamente, como lo hizo el prestigioso profesor Vélez con Bastián, que en el caso que nos ocupa, envió un aval al Instituto de Segunda Enseñanza de Camagüey donde existían un grupo de mecanismos de violencia simbólica preconfigurados y que impedían que los blancos pobres o los negros pudiesen cumplir con las exigencias para el ingreso; indudablemente este documento sirvió para que su exalumno fuese admitido. Como existían leyes contra la discriminación racial la negación para que los negros entraran al plantel no era explícita operaba desde el currículo oculto.

Su tránsito por el Instituto de Segunda Enseñanza de Camagüey comenzó a partir del 25 de septiembre de 1924, a los trece años de edad, cuando fue admitido oficialmente al haber obtenido la calificación de "aprovechado". Entre los tres miembros del tribunal designado para los exámenes de ingreso, en el expediente consultado, de forma legible, aparecen los nombres de los catedráticos doctores que fungieron como Presidente, Lorenzo Verdecia; Vocal, Emilio Biosca, además de otro Doctor que fue el Secretario, que en vez de su nombre y apellidos plasmó su firma.

La trayectoria de estudiante de Bastián Milán por el Instituto fue algo exitosa aunque no exenta de dificultades, en un contexto de inequidades tenía conciencia plena que, por su condición de negro, tenía que redoblar esfuerzos. Cuando se revisa la antigua documentación del Instituto de Segunda Enseñanza de Camagüey, referida a los años en que cursó Bastián Milán (1924-1928), resulta fácil inferir que fue un buen estudiante.

En el año 1925 matricula las asignaturas de: Aritmética, Álgebra, Geometría Trigonométrica, Geografía Universal, Historia Universal, Francés I y Francés II. Aprobando todas las asignaturas, presentando dificultades con Álgebra y obteniendo máximas calificaciones en los dos cursos de francés.

Si se analiza el último curso por el que transitó en el Instituto de Segunda Enseñanza (19271928) se puede afirmar que fue un alumno aventajado en las ciencias, el plan oficial de estudio del plantel comprendía para el último año las asignaturas de: Calistenia, un segundo curso de Física, Química, Historia Natural, Enseñanza Cívica y Agrimensura; obtuvo calificaciones de sobresaliente en: Física, Química, Enseñanza Cívica y Calistenia; aprobó la Historia Natural y mostró dificultades en la asignatura de Agrimensura. 


\section{Formación profesional de Fernando Ramón Bastián Milán}

Una vez concluido el Instituto de Segunda enseñanza, el 13 de agosto de 1928 recibe el título de Bachiller en Artes y Letras y matricula la carrera de medicina en la Universidad de La Habana pero sucede un inconveniente, debido a los conflictos políticos muchos de los centros auspiciados por instancias de gobierno, fueron frecuentemente cerrados, en el caso de la Universidad de La Habana se cerró tras concluir el primer semestre de clases en 1930.

Debido a estas condicionantes los alumnos con posibilidades económicas podían estudiar en el extranjero en países como Estados Unidos, España y Francia. El padre de Bastián Milán decide enviarlo a Francia por el tema de la discriminación racial pues Francia era un país más abierto y en los demás había más exclusión. Tiempo después de haber llegado a Francia su padre desaparece en él ciclón del 32, en Santa Cruz del Sur, lo cual le hace más difícil su permanencia en el extranjero pero su madre lavaba y planchaba ropa para obtener dinero y solventar sus estudios, así como amigos que también ayudaron.

En Francia estudiaron con Bastián otros médicos camagüeyanos negros, que por su quehacer profesional gozaron de gran prestigio en la región como fueron: el Doctor Manuel Beyra Alemañy, Renato Caballero y Marcos Meruelo Torriente que fue muy buen amigo suyo. Manuel Beyra Alemañy era pediatra, Renato Caballero cardiólogo y Meruelo era dermatólogo.

A los 27 años, el 4 de abril de 1938 se graduó de Doctor en Medicina en Francia, en la Sorbona y decide regresar a Cuba en ese mismo año, llega unido sentimentalmente con una enfermera francesa que conoció cuando realizaba sus prácticas médicas en el hospital de París pero esta mujer no se adaptó a vivir en Cuba y regresó a su país. De forma oficial, en el año 1959, se casó con Noema Manso Gonzáles y tuvo dos hijos: Luis Herminio Bastián Manso y Fernando Romualdo Bastián Manso; además tuvo un tercer hijo, fuera del matrimonio, al que le pusieron por nombre Fernando Bastián de la Torre, el cual murió muy joven de una bronco aspiración en el río de Arroyón, en Camagüey.

Luego que Fernando Ramón Bastián Milán regresara a Cuba, para poder ejercer como médico tiene que revalidar el título en la Universidad de la Habana, autorizado y suscrito conjuntamente con el Decano de la Facultad de Medicina de La Habana el 9 de enero de mil novecientos treinta y nueve. A partir del 25 de mayo 1939 comienza la época laboral en Cuba, específicamente en Camagüey. (Colegio Médico de Camagüey:1939,188.) Desde 1939, recién graduado, aparece registrado formando parte del Directorio Médico de la Provincia. A las claras se puede entender, que a pesar de su probada capacidad intelectual, también el acceso al empleo se le facilitaba más porque era un hombre de magníficas relaciones sociales.

Perteneció a la burguesía negra camagüeyana, formó parte de las asociaciones de instrucción y recreo para negros y mulatos, fue amigo de personalidades del ámbito sociocultural y político como por ejemplo de: Olga Guillot; Candita Batista; Filo Torres; el boxeador Kid Gavilán y Josefh Adam, quien fuera Cónsul General de Haití en Camagüey y Santa Clara. 
Poseía un vasto conocimiento de instrumentos culturales valorados por la sociedad burguesa, dominaba a la perfección los idiomas Inglés y Francés, tanto así que fue llamado como catedrático para impartir clases de Francés en la escuela Normal para Maestros. Estudió violín desde los siete años y lo tocaba con gran habilidad, al igual que la guitarra, además de que cantaba muy bien. De manera excepcional este negro logró por sus méritos, sus probadas competencias y por su capital cultural alcanzar movilidad social ascendente.

El contacto con la cultura francesa dejó una huella indeleble en la formación profesional de Bastián Milán. En los pocos boletines médicos que se atesoran en la sala de Fondos Raros y Valiosos en la Biblioteca Provincial Julio Antonio Mella de Camagüey, se encontraron dos artículos publicados, escritos por el Doctor Bastián Milán titulados: Intoxicación por el sublimado(Colegio Médico de Camagüey: 1939. p.44-45) y Ácido Mandélico y Sulfanilamida (Colegio Médico de Camagüey: 1939, p.42-43) donde el científico parte de realizar consideraciones de orden práctico sobre el tratamiento de la Nefritis Aguda de la Escuela Francesa y Nefrosis de la Escuela Alemana por la Ingestión del Sublimado. El contacto con otras culturas favoreció el éxito profesional de Bastián Milán; en su obra publicada se aprecia una coherencia cognoscitiva con lo aprendido en la escuela de medicina francesa lo que posibilitó también que emitiera diagnósticos muy certeros.

La familia conserva algunos textos que fueron propiedad de Bastián Milán por los que estudió en la Facultad francesa de Medicina, escritos también en Francés y por científicos de esa misma nacionalidad, libros que siempre consultaba como: Thérapeutique usuelle des maladies de appareil respiratoire (Terapéutica usual de las enfermedades del aparato respiratorio) escrito por Alfred Martinet, Ancien Interne des Hópitaux de París(Anciano interno del Hospital de París); Quelques verités premiérés (ou soi-disant telles) en Chirurgie Abdominale (Algunas verdades primordiales (o sea esas) en Cirugía Abdominal) de H. Mondor, professeur agrégué de pathologie chirurgicale á la Faculté de Medécine de París Chirurgien de l'Hópital Bichat(profesor agregado de patología quirúrgica de la Facultad de Medicina de París, Cirujano del Hospital Bichat).

La apropiación de elementos procedentes de esta cultura foránea hizo que el ilustre médico se distinguiera por encima de los otros galenos de cualquier color de piel y fuese bien aceptado en los círculos de poder, sus modos, costumbres, ritualidades, práctica religiosas católicas estaban a la altura de la clase hegemónica que pautaba y constituía la norma: todo el día vestía de traje y corbata, incluso para consultar; saludaba en francés, escuchaba música y leía libros en esa lengua y era el profesor principal de Gramática Francesa en el Instituto de Segunda Enseñanza. Sus pupilas lo califican como muy afrancesado, apuesto y de exquisito gusto.

\section{Labor profesional en Camagüey}

Las consultas privadas en Camagüey de Fernando Ramón Bastián Milán tuvieron varias sedes: su primer consultorio fue en Independencia No 66, después en San Fernando 290 y por último Cristo 10, esta última se mantuvo hasta los últimos días de su vida. Dentro del desempeño profesional del Doctor Bastián Milán existe un reconocimiento a su entrega y fidelidad por las personas pobres y discriminadas. Uno de sus nietos expresó que siempre recordaba una frase que decía su abuelo: - la gente blanca y rica me marginó mucho, y juré 
nunca cobrarles a los pobres- como en aquel tiempo había tanto racismo, él trataba siempre de favorecer a estas personas pobres y a los negros como los más desventajosos socialmente. Las personas lo llamaban a él y al doctor Carbonell los médicos de los pobres.

A los pacientes que no tenían recursos Bastián Milán los atendían sin cobrarles nada y hasta la medicina se la daba gratis, a los campesinos humildes que venían a tratarse desde los municipios y que no tenían con qué pagar, les llevaban a la consulta gallinas envueltas en periódico o papel cartucho, traían esto como regalo y agradecimiento, también plátano, maíz, frijoles, queso, arroz. Muchas veces lo paraban en la calle y atendía a todo el mundo, hablaba, saludaba, él decía que le daba a cada persona el valor que merecían porque todos tenían un grado de importancia. Fue el médico de casi todas las personas que vivían en la Calle Cristo.

En la época republicana todavía, no se conocían los especialistas, de modo que el médico tenía que hacer la medicina completa. Bastián Milán fue un médico que hacía de todo, lo mismo un parto que una cirugía, pues en aquel tiempo no habían especialidades, realizó más de doscientos partos, incluso uno de ellos en un autobús.

Laboró como médico interno y laboratorista del Hospital General, trabajó con el doctor Hugo Pedroso cuando el hospital estaba ubicado donde está hoy el hogar de ancianos, se especializó en vías urinarias y ejerció también como médico deportivo.

Las personas que acudían a su consulta salían siempre satisfechas, dentro de su práctica médica, orientaba el uso de fórmulas para que se confeccionaran en los dispensarios farmacéuticos, llenaba las recetas con gran facilidad pues tenía un vasto conocimiento de farmacología, decían que los doctores Meruelo y Bastián cuando hacían las fórmulas magistrales tenían al menos catorce productos que se sabían de memoria. Hacia jarabes lo mismo para un dolor de cabeza que de estómago, siempre tenía la solución para cualquier dolencia.

Bastián Milán como era tan muy conocedor de los fitofármacos y psicofármacos en sus formulaciones, recetaba muchos compuestos empleando productos químicos como: $\mathrm{Hi}-$ posulfito de Sodio, Cafeína, Solución de Éther, Eucalipto, Benjuí, Tolú, Yoduro de Potasio, con su respectiva dosificación y combinaciones. Bastián y Meruelo fueron médicos que se pueden considerar los precursores del uso de fórmulas médicas en Camagüey.

Fernando Ramón Bastián Milán rompió con los mitologemas antropológicos construidos socioculturalmente para los negros, asociado a que tenían las capacidades intelectuales reducidas y condiciones biológicas para destacarse en las llamadas cosas de negros: deportes; cantos; bailes de rumba; apropiación de determinados instrumentos musicales, sobre todo los percutidos; prácticas de religiones de origen africano; vulgaridad; confinamiento a los espacios del solar; marginalidad y criminalidad. Este hombre grande fue la antítesis de esa realidad edificada para hombres y mujeres que fueron etiquetados por tener un color de piel específico.

Después del triunfo de la Revolución Cubana fue de los pocos doctores que permaneció en el país pues comprendió que el proceso revolucionario favorecería a los pobres y dis- 


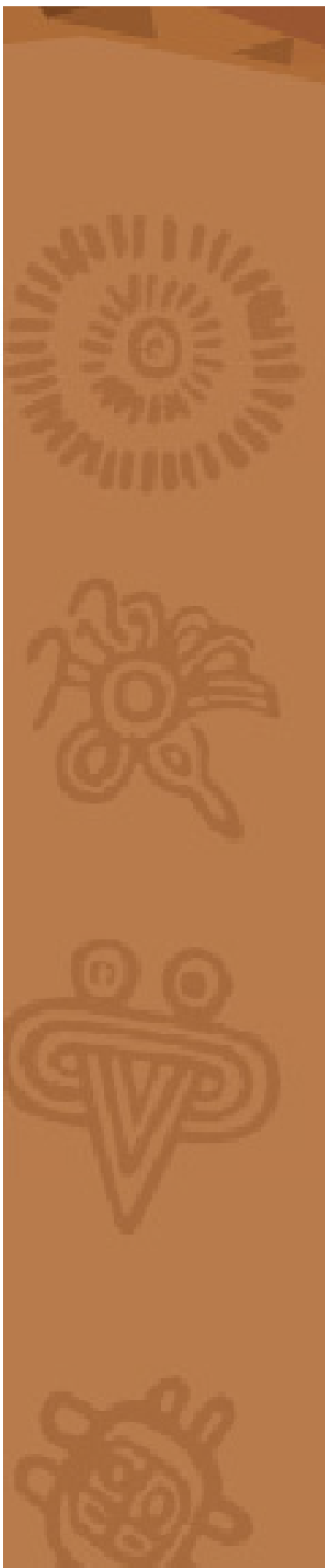

criminados, estuvo vinculado a las acciones políticas de su tiempo formó parte de las Unidades Regulares de Milicias de la Defensa Popular; participó en movilizaciones; marchas revolucionarias; en la Campaña de Alfabetización se integró como médico del tren de los jóvenes que se iban a capacitar en Varadero para luego ir a la alfabetización.

En el año 1962 participó, también como médico, de la movilización de la Crisis de Octubre o Crisis de los Misiles entre Estados Unidos y Cuba, siendo un pequeño burgués aceptó ser movilizado, pues hubo médicos que no lo aceptaron y él fue el primero en acceder ante él llamado a la movilización militar.

Trabajó ininterrumpidamente en la Policlínica Centro hasta sus 83 años cuando en 1992 decide dejar de consultar en la institución de salud. Su paso por la institución de salud fue memorable se desempeñó como médico junto al doctor Casalís en el Sector número 1 cuando se asumió la estructura de Sectores y las personas, aunque por disciplina asistían al sector que le correspondía, esperaban después pacientemente para escuchar el visto bueno del sabio Bastián. Era un médico muy certero en sus diagnósticos, las familias quedaban tranquilas luego de escuchar su criterio. Muere con 88 años, el 4 de noviembre de 1999 a causa de un accidente cerebro vascular.

Fue una enorme pérdida para la familia, pero también para Camagüey, Cuba y el mundo porque no hay persona a la que se le pregunte por él y no lo recuerde como el gran médico de los pobres que fue; aquel ser humano de gran estatura física y simbólica, supo sublimar prejuicios, inequidades y discriminaciones múltiples para ubicarse en el mismo nivel que los blancos más connotados de su tiempo. Desarmó el mito de inferioridad demostrando que no existen razas solo hombres.

\section{Conclusiones}

La investigación realizada permitió describir aspectos significativos de la vida social y profesional de Fernando Ramón Bastián Milán, médico negro camagüeyano que se consagró a atender a los más pobres y discriminados de la región. Este galeno ejerció en Camagüey a partir de 1939 hasta el año 1992 cuando dejó de atender en la consulta de la Policlínica Centro.

Fue un hombre que supo afrontar la discriminación racial de su tiempo rompiendo las barreras impuestas por la colonialidad y demostrando que el color de la piel no es lo que define la grandeza de los seres humanos.

Las redes relacionales, la herencia sociofamiliar y sus probados méritos, son algunos de los aspectos que contribuyeron al desarrollo y éxito profesional de Bastián Milán.

Rompió con los estereotipos construidos históricamente para personas de un determinado color de piel, demostrando que los negros deben de tener oportunidades y acceso a la educación e instrucción, como vía a la movilidad social ascendente, a aprendizajes y desaprendizajes que son esenciales para la convivencia y reconocimiento social. 
Como pocos médicos del país estudió en Francia, en la Sorbona, se graduó, revalidó su título en la Universidad de La Habana y se estableció en la ciudad de Camagüey, donde se ganó reconocimiento y prestigio.

Su contribución social en el campo de la medicina reside, justamente, en la entrega a los pobres y a personas de color de piel negra, segmento poblacional ignorado por los profesionales blancos; contó con una vasta producción teórica científica; fue pionero de los médicos de familia y precursor del uso de fórmulas como acciones curativas.

A pesar de que formaba parte de la burguesía negra camagüeyana se insertó, sin ningún tipo de contradicción, al proceso revolucionario cubano, después de 1959 y participó como médico en varias de sus acciones.

\section{Referencias bibliográficas}

Colegio Médico de Camagüey. (1939).Colegio médico de Camagüey. Boletín del Colegio Médico de Camagüey: Revista camagüeyana de temas médicos (6),42-43.

Colegio Médico de Camagüey. (1939). Años de ejercicio profesional en la ciudad de Camagüey. Boletín del Colegio Médico de Camagüey: Revista camagüeyana de temas médicos (2) ,188-189.

Colegio médico de Camagüey. (1939). Boletín del Colegio Médico de Camagüey: Revista camagüeyana de temas médicos (1),44-45.

Colegio Médico de Camagüey. (1939). Boletín del Colegio Médico de Camagüey: Revista camagüeyana de temas médicos (6):42-43.

Conde, A. (2017).Pensamiento pedagógico cubano 1902-1920. Crítica y conciencia en la República. La Habana: Editorial de Ciencias Sociales.

De La Fuente, A. (2014). Una nación para todos: raza, desigualdad y política en Cuba 1900-2000. La Habana: Ediciones Imagen Contemporánea.

Duarte G. (2013). Las Sociedades de Negros y Mulatos en la ciudad de Pinar del Río (1902-1963). Pinar del Río: Ediciones Loynaz.

Expediente de Fernando Ramón Bastián Milán. (1924). Archivo Histórico Provincial de Camagüey. Camagüey: Fondo del Instituto de Segunda Enseñanza, expediente 3067, legajo no. 175.

García, O.C. (2013). Educación. En: Álvarez Álvarez L.E, García Yero O.C, Cento Gómez E.E. La luz perenne. La cultura en Puerto Príncipe (15141898). Santiago de Cuba: Editorial Oriente. 
Inscripción de Nacimiento de Fernando Ramón Bastián Milán. (1911). Registro Civil Provincial de Camagüey, Tomo 94, folio 178.

Revelo, P., Rodríguez Méndez, V., \& Caballero Rivacoba, M. T. (2018). Contribución social de médicos camagüeyanos a los colegios religiosos católicos: el estigma de ser negro. Revista Humanidades Médicas,(3), 749-765. http://humanidadesmedicas.sld.cu/index.php/hm/article/ view/1335/html_71

Sanger, J.P. (1899). Informe sobre el censo de Cuba 1899. Tabla XXXIII: Profesiones especiales, por sexos, razas y nacionalidad. Washington: Imprenta del Gobierno.

Tamames, M.A. (2014). Calles y callejones de Camagüey. Entre la Leyenda y la historia. Camagüey: Editorial Ácana.

Entrevistas:

Acuña. M. (2019) Entrevista a José Gabriel Bastián Cadalso. Camagüey: Iglesia Nuestra Señora de la Merced.

Acuña M. (2019). Entrevista a Giondano Bastián Cordero. Colombia: Medellín.

Acuña, M. (2020). Entrevista a María del Carmen Pontón Guillemí, Arsenio Leandro Morfa Mestril, Xiomara Bárbara Gil Blanco. Camagüey: Casa Natal de Carlos. J. Finlay.

Revelo, P. Entrevista a Emilia Álvarez Aguiar. Camagüey: Museo Ignacio Agramonte. 
Pavel Revelo Alvarez

Doctorante del programa de Ciencias Sociológicas de la Universidad de La Habana. Máster en Cultura Latinoamericana por el Instituto Superior de Arte de La Habana (ISA). Licenciado en Estudios Socioculturales por la Universidad de Camagüey. Vicepresidente de la Cátedra Honorífica de Antropología "Fernando Ortiz", forma parte de la Red Nacional de Educadores Populares del Centro Martin Luther King, Profesor Auxiliar de la Universidad de Camagüey y del Departamento de Estudios Socioculturales, con posgrados en: Antropología, Antropología del Turismo, Sociología de la Cultura y Sociología de la Educación. Está integrado como miembro de los proyectos nacionales de Investigación de: Desarrollo Social y su articulación con el desarrollo local y comunitario, liderado por la Dra.C. María Teresa Caballero Rivacoba y al proyecto Lenguaje y representación en la cultura urbana camagüeyana y nacional, liderado por el Dr.Cs. Luis Eduardo Álvarez Álvarez. Es líder del proyecto investigativo Instituciones Socioculturales. Cuenta con varias publicaciones de perfil socioantropológico en revistas como Humanidades Médicas, Arcada, Ixaya, Del Caribe; además con dos libros sobre cultura culinaria de los haitianos, publicados por las editoriales Ácana y Mc Pherson.

Circunvalación Norte, km 5 1/2, Camagüey, Cuba. C.P. 70200.

Maricarmen Acuña Pontón

Especialista de la Oficina del Historiador de la Ciudad de Camagüey, colaboradora del proyecto de Video Arte. Licenciada en Gestión Sociocultural para el Desarrollo por la Universidad de Camagüey "Ignacio Agramonte Loynaz." Colaboró además con dos proyectos investigativos: Lenguaje y representación en la cultura urbana camagüeyana y nacional e Instituciones Socioculturales, de este último se derivó su trabajo de diploma para obtener la Licenciatura, titulado: Biografía socioantropológica de Fernando Ramón Bastián Milán que ha tenido reconocimientos significativos en la presentación de eventos provinciales, nacionales e internacionales. Ha cursado posgrados en: Metodología de la Investigación, Educación Popular, Estudios de Género y en Sociología. Es miembro de la Cátedra Honorífica de Antropología "Fernando Ortiz."

Calle Carmen entre San Ramón y Martí, Camagüey , Cuba. C.P. 70100. 